drivers, many insulin treated drivers stop driving voluntarily because of failing vision and do not renew their licenses. ${ }^{56}$ The assessment of vision of non-insulin dependent diabetic drivers should therefore not be neglected, and worsening vision from cataracts or retinopathy should be reported to the licensing agency.

Loss of visual fields may result from localised retinal ischaemia in preproliferative diabetic retinopathy $(\mathrm{C} \mathrm{K} \mathrm{L}$ Chee and D W Flanagan, unpublished data) and from retinal destruction by panretinal laser photocoagulation..$^{13}$ The measurement of visual fields by perimetry is therefore required for evaluating vision in diabetic drivers who have received photocoagulation. Drivers who require photocoagulation should be warned of possible peripheral field loss, which may jeopardise renewal of their driving licence. Dark adaptation may also be affected, and drivers with treated retinopathy may experience difficulty driving at night. Cataracts are associated with excessive headlight glare.

The evidence that diabetic drivers have a higher rate of road traffic accidents is limited, but many motor insurers still quote higher premiums for diabetic drivers. ${ }^{3}$ Most recent studies have shown either very similar reported accident rates for diabetic and non-diabetic drivers, ${ }^{56815}$ or only a slight increase. ${ }^{16}$ These surveys do not, however, include fatal accidents, in which confirmation of a diabetic cause, such as hypoglycaemia, is usually impossible. In addition, accident rates may be lowered by diabetic drivers with advancing complications removing themselves from the active driving population ${ }^{5}$ and by the efforts of the regulatory authority to exclude high risk drivers. Although Songer suggested that restricting the driving licences of diabetic drivers represents unjustified discrimination, ${ }^{17}$ it is important to acknowledge that diabetic problems constitute potential hazards to road safety.

Consultant Physician,

BRIAN M FRIER

Department of Diabetes,

Royal Infirmary,

Edinburgh EH3 9YW

1 Frier BM, Matthews DM, Steel JM, Duncan LJP. Driving and insulin-dependent diabetes. Lancet 1980;i:1232-4.

Steel JM, Frier BM, Young RJ, Duncan LJP. Driving and insulin-independent diabetes. Lancet 1981;ii:354-6.

3 Frier BM, Sullivan FM, Stewart EJC. Diabetes and insurance: a survey of patient experience. Diabetic Med 1984;1:127-30.

4 Saunders CJP. Driving and diabetes mellitus. BMF 1992;305:1265.

5 Stevens AB, Roberts M, McKane R, Atkinson AB, Bell PM, Hayes JR. Motor vehicle driving among diabetics taking insulin and non-diabetics. BMF 1989;299:591-5.

6 Eadington DW, Frier BM. Type 1 diabetes and driving experience: an eight-year cohort study. Diabetic Med 1989;6:137-41.

7 Fisher BM, Storer AM, Frier BM. Diabetes, driving, and the general practitioner. BMF 1985;291:181-2.

8 Songer TJ, La Porte RE, Dorman JS, Orchard JJ, Cruickshanks KJ, Becker DJ, et al. Motor vehicle accidents and IDDM. Diabetes Care 1988;11:701-7.

9 Cox D, Gonder-Frederick L, Driesen N, Clarke W. Driving performance of type 1 patients during euglycemia, moderate and severe hypoglycemia. Diabetes 1991;40(suppl 1):557A. (Abstract.)

10 Pramming S, Thorsteinsson B, Theilgaard A, Pinner EM, Binder C. Cognitive function during hypoglycaemia in type 1 diabetes mellitus. BMY 1986;292:647-50.

11 Widom B, Simonson DC. Glycemic control and neuropsychologic function during hypoglycemia in patients with insulin-dependent diabetes mellitus. Ann Intern Med 1990;112:904-12.

12 Hepburn DA, Patrick AW, Eadington DW, Ewing DJ, Frier BM. Unawareness of hypoglycaemia in insulin-treated diabetic patients: prevalence and relationship to autonomic neuropathy.

13 Frank RN. Visual fields and electroretinography following extensive photocoagulation. Arch Ophthalmol 1975;93:591-8.

14 Williamson TH, George N, Flanagan DW, Norris V, Blamires T. Driving standard visual fields in diabetic patients after panretinal laser photocoagulation. In: Vision in Vehicles III. (Proceedings). Amsterdam: North Holland, 1991:265-72.

16 Chantelau E, Dannbeck S, Kimmerle R, Ross D. Zur Verkehrstüchtigkeit insulin-behandelter Diabetiker. Münchener Medizinische Wöchenschrift 1990;132:468-71.

17 Hansotia P, Broste SK. The effect of epilepsy or diabetes mellitus on the risk of automobile accidents. N Engl F Med 1991;324:22-6.

18 Songer TJ. Drivers with diabetes. Innocent until proven guilty. Diabetes Care 1989;12:233-4

\title{
Glasgow, Edinburgh, and the health divide
}

\section{Is it ever too late for prevention?}

As the new edition of The Health Divide reminds us, a concern that widening health inequalities may have been responsible for Britain's slipping position in the international health league was one of the reasons for commissioning the Black report. ${ }^{\prime}$ Health inequalities are almost certainly not a matter of the distribution of health around an independently determined mean. Rather, increased relative deprivation tends to lower national standards of health because it produces few, if any, offsetting health benefits among the more privileged. Thus countries like Sweden, with smaller differences in health between socioeconomic groups, also have lower overall mortality. ${ }^{2}$

Similarly, in Japan, where social class differences in mortality have narrowed (in contrast with the British experience), national mortality has fallen spectacularly over the past few decades. ${ }^{3}$ The credibility of the underlying relation between national mortality and the scale of relative deprivation has recently been confirmed by the observation that the nations with the lowest overall mortality tend to be those with the narrowest differences in income. ${ }^{4}$ More rapid improvements in national standards of health are therefore likely to depend primarily on reducing the burden of relative deprivation responsible for health "inequalities."

The research summarised in The Health Divide and work on the impact of medical services on the health of populations ${ }^{5}$ have emphasised again that social and economic factors are the overriding determinants of health in modern society. This partly reflects the extent to which the human environment is now a socioeconomic rather than a natural entity. But despite the growing understanding of the power of socioeconomic circumstances there are widely divergent views on how they exert their influence on health.

The latest grist to the mill is provided by a study of differences in mortality between Glasgow and Edinburgh since 1931. ${ }^{\circ}$ Compared with Edinburgh, Glasgow has a longstanding mortality disadvantage, reflecting the poorer socioeconomic circumstances of the inhabitants. What excites particular interest is that Glasgow's mortality disadvantage remains roughly constant within each cohort for all ages over 25 . Whether the comparisons are made at age 25 or 65 , age specific death rates show that mortality risks for Glaswegians are the same as those for people from Edinburgh more than three and a half years their senior. (The log death rates are linear within cohorts and parallel between the two cities.)

Have these years been lost by age 25 , or is the environmental pressure of mortality in adulthood greater in Glasgow? Does relative deprivation cast a "long shadow" forward, putting Glaswegians at an unchanging disadvantage throughout their adult lives, or are we simply seeing the impact on health of the constant daily exposure to the poorer circumstances in which Glaswegians continue to live? The long shadow interpretation finds support in the reported early precursors of adult heart disease, obesity, and respiratory illness. ${ }^{7-9}$ But how far adult disease and events in early life are linked biologically, by irreversible physiological damage, or socially, by continuing relative deprivation, remains controversial. ${ }^{11}$ Although 
cogent evidence has been given of the likely long term effects of an adverse environment during critical stages of growth, ${ }^{12}$ cohort studies able to distinguish between the effects of early and later deprivation suggest that later deprivation is the stronger influence on adult health. ${ }^{13}$

The difficulty of illuminating the processes influencing mortality in Glasgow and Edinburgh comes from the constancy of their socioeconomic and mortality differences. The divergent experiences of other populations may be more revealing. Middlesbrough's excess mortality over Sunderland's was not apparently prefigured by socioeconomic differences early in life. ${ }^{14}$ In the United States the mortality advantage enjoyed by the closely knit Italian community of Roseto over the neighbouring town of Bangor, in Pennsylvania, rapidly disappeared among older women and men under 65 as social cohesion fell and rates of myocardial infarction rose. ${ }^{15}$ Similarly, the rise in mortality in several east European countries does not seem to have waited for cohort effects to work their way through before affecting mortality at older ages. ${ }^{16}{ }^{17}$ Perhaps the parallel rate of rise in mortality with age in Glasgow and Edinburgh indicates that the same factors operate in the two cities but at different levels of intensity.

Whether Glasgow's mortality disadvantage is a function of the long term effects of early deprivation or of the constant pressure of circumstances throughout life, we clearly cannot afford to ignore environmental influences on health at any age. At a time when other governments, originally stimulated by the Black report, are taking practical steps to tackle socioeconomic disadvantage in health ${ }^{1}$ it is ironic that the only tangible sign that the British government recognises the problem remains the deprivation payments made to the small proportion of hard pressed general practitioners working in areas high on the Jarman index.

RICHARD G WILKINSON

Senior Research Fellow,

Trafford Centre for Medical Research,

University of Sussex,

Brighton BN1 9RY

Whitehead M. The health divide. In: Inequalities in Health. London: Penguin, 1992.

2 Vagero D, Lundberg O. Health inequalities in Britain and Sweden. Lancet 1989;ii:35-6.

3 Marmot MG, Davey Smith G. Why are the Japanese living longer? BMf 1989;299:1547-51

4 Wilkinson RG. Income distribution and life expectancy. BMF 1992;304:165-8.

5 Mackenbach JP, Bouvier-Colle MH, Jougla E. Avoidable mortality and health services: a review of aggregate studies. F Epidemiol Community Health 1990;44:106-11.

6 Watt GCM, Ecob R. Mortality in Glasgow and Edinburgh: a paradigm of inequality in health f Epidemiol Community Health 1992;46:498-505.

Barker DJP, Osmond C, Law C. The intra-uterine and early postnatal origins of cardiovascular
B. disease and chronic bronchitis. $f$ Epidemiol Community Health 1989;43:237-40.

8 Law CM, Barker DJP, Osmond C, Fall CHD, Simmonds SJ. Early growth and abdominal fatness in adult life. 7 Epidemiol Community Health 1992;46:184-6.

9 Mann SL, Wadsworth MEJ, Colley JRT. Accumulation of factors influencing respiratory illness in members of a national birth cohort and their offspring. I Epidemiol Community Healt 1992;46:286-92.

10 Elford J, Shaper AG, Whincup P. Early life experience and cardiovascular disease-ecological studies. $\mathcal{F}$ Epidemiol Community Health 1992;46:1-8.

11 Ben-Shlomo Y, Davey Smith G. Deprivation in infancy or in adult life: which is more important for mortality risk? Lancet 1991;337:530-4.

12 Barker DJP, ed. Fetal and infant origins of adult disease. London: British Medical Journal, 1992.

13 Power C, Manor O, Fox J. Health and class: the early years. London: Chapman and Hall, 1991.

14 Phillimore PR, Morris D. Discrepant legacies: premature mortality in two industrial towns. Soc Sci Med 1991:33:139-52.

5 Egold B, Lasker J, Wolf S, Potvin L. The Roseto effect: a 50-year comparison of mortality rates. Am f Public Health 1992;82:1089-92.

16 Minev D, Dermendjieva B, Mileva N. The Bulgarian country profile: the dynamics of some inequalities in health. Soc Sci Med 1990;31:837-46.

17 Wnuk-Lipinski E. The Polish country profile: economic crisis and inequalities in health. Soc Sci Med 1990;31:859-66.

\title{
Getting rational over rationing
}

\author{
Firstly, find out what works
}

The week of the autumn statement on next year's government spending was a good time to hold a conference on rationing health care, ${ }^{1}$ and last week there were two.* A surprising amount of common ground emerged despite the obvious differences (the great and the good in serried ranks at the Royal College of Physicians; political activists and pensioners' representatives in the Central Hall of the Young Women's Christian Association). The points of agreement included dissatisfaction with the term "rationing" and a recognition that current data on outcomes are inadequate to allow informed choices. Everyone wanted future rationing decisions to be explicit rather than implicit, and many people were in favour of public participation in the decision making process.

Importing the word "rationing" into the debate is regarded as unhelpful because it describes, unnecessarily emotively, an everyday activity: choices have always been made between competing demands for scarce resources and always will be. What are needed are ways of deciding how to allocate these scarce resources: in the words of Professor Alan Maynard, "to maximise health to the greatest extent at the least cost."

Unfortunately, our ignorance of what medical interventions work and what they cost prevents this. New Zealand and the Netherlands ${ }^{2}$ both want to restrict their funding to a core of treatments that work but are finding the task of identifying these difficult. Salvation is expected to come through the application of outcome measures and economic evaluations of treatment. The chief medical officer, Dr Kenneth Calman, said that the government was vigorously promoting these. $\mathrm{He}$ listed the outcomes clearing house, the Effective Health
Care bulletins, health technology assessment by the NHS research and development programme, the Cochrane Centre for collecting and disseminating the results of randomised clinical trials, medical audit, and the clinical outcomes group to be jointly chaired by him and the chief nursing officer.

To date, doctors have taken most decisions about limiting services to certain patient groups, particularly elderly people -whose access to renal dialysis and coronary care units has been restricted by age limits. Often what have looked like "clinical" decisions have been no such thing. ${ }^{3}$ Few people at either meeting wanted this "implicit rationing" to continue. Decisions about which services would and would not be offered and the criteria used to make these decisions should be made explicit so that they can be debated. "Society can then debate what level of service it expects to be provided and what it can afford," said Dr W M G Tunbridge, a general physician at Newcastle General Hospital. "Doctors should not arrogate to themselves these decisions," said Professor J Grimley Evans, a geriatrician at Oxford's Radcliffe Infirmary. These are political decisions: "in a democracy they are the responsibility of the elected representatives," he said.

Involving the public in decision making has its problems. In the most famous experiment, in Oregon, they tried very hard to incorporate "community values" in ranking conditions according to their call on public finances. But the people who attended the public meetings and took part in the telephone surveys were probably not representative of those whose medical cover was going to be affected by the changes 